\section{Dominion Tributes}

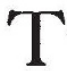
RIBUTES to Lord Rutherford continue to appear, written in many cases subsequent to the numerous appreciations in Nature. Prof. T. H. Laby, professor of natural philosophy in the University of Melbourne, has published an article in the January number of the Australian National Review. Dr. C. M. Focken, lecturer in physics at the University of Otago, N.Z., has given a good summary (19 pp.) of Rutherford's life and work (Otago : N.Z. University. London: Whitcombe and Tombs, Ltd.). Dr. E. Marsden, now Director of the New Zealand Department of Scientific and Industrial Research, has written an interesting account of Rutherford's origin and youth in the New Zealand Railways Magazine for January and February, 1938.

The chief feature of these contributions is the insistence on the great benefits to the Dominions of Rutherford's visits and influence. Prof. A. Norman Shaw, of McGill University, has already pointed out that physies acquired a new status in Canada dating from that period when Rutherford 'set the St. Lawrence on fire' at the beginning of the century. During the visit of the British Association to South Africa, Rutherford spoke at several of the colleges, and the gratitude conveyed to him always expressed fresh interest and stimulation. In Australia and New Zealand his lecture tours were semi-regal, and Rutherford endeavoured in vain to curb the enthusiasm which would manifest itself in functions, students dragging his car, and even mayors and brass bands. The fact is that wherever he went-Europe, America or the Antipodes-he was one of Great Britain's best ambassadors.

Rutherford was aware, from personal experience, of the difficulties which most physicists have to face in working in the Dominions, sometimes rather isolated, with a shortage of co-workers to discuss developments, and with delay in acquiring information and delay in publication of results.

As Prof. Laby writes: "Although he left New Zealand as a young graduate, Rutherford never forgot his native land, and he rendered it many scientific services. This attitude was expressed, too, in the numerous connexions which he maintained with physicists in the Dominions: the many helpful letters which he wrote to them must have been no small tax on his energies. His experience in Canada, his visits to Australia, New Zealand and South Africa, gave him a quite rare perception of the difficulties of scientific work in the Dominions. He went to great pains to accept in his laboratory research students from the Dominions, and few were so quick to recognize in them real ability, if they possessed it, than he. . . . It is conventional to speak of the loss which a man's death creates, but it is no mere tribute of that kind to say Rutherford's death is a very real loss to physics in the Dominions."

So, too, Dr. Focken : "Although he was essentially modest and unassuming, his dominating presence commanded success. In view of his tremendous energy and blazing intellectual fire, it is not at all surprising that he got things done. . . . It is related that his students after a period of fear, learned to love and respect him. His enthusiasm

\section{to Lord Rutherford}

infected them. Once a day he walked round the whole laboratory to talk to each student and discuss difficulties which had arisen and possible lines of advance in the student's research. He spoke of his forty or fifty students as his family, to whom he acted as 'father, grandfather and mother'. He was always pleased to take into his laboratory any young men from the Dominions who had had proper training, provided he had the accommodation. At one time he had so many of these students that he could not accept any from foreign countries I recall his generosity in offering to allow me to work in his laboratory for a brief period at a time when he had many other applications from students willing to stay longer. Just as generations of overseas students at Oxford took delight in the open house kept on Sunday afternoons by Sir Charles and Lady Sherrington, so at Cambridge, students who attended the Cavendish Laboratory recall with great pleasure the informal tea parties in the Rutherford home."

Dr. Focken also mentions several interesting facts relating to Rutherford's early life which are not well known in Great Britain. His father, James Rutherford, was born a century ago in Perth, Scotland, and was taken by his parents to New Zealand while still a child. He became a wheelwright like his father and in 1866 married Martha Thomas. Ernest Rutherford was the fourth child of twelve and was born at Nelson on August 30, 1871. The family afterwards moved to Havelock, twenty-five miles east of Nelson and worked "an outback farm". From the age of eleven to sixteen, Ermest attended the Havelock school under Mr. Jacob Reynolds and won a provincial scholarship tenable for two years at Nelson College. Here he won many prizes, became dux of the College and gained a Junior University scholarship at Canterbury College, Christchurch. In 1893 he took his M.A. degree with first-class honours in mathematics and physics and next year was awarded an 1851 Exhibition Science scholarship with which he entered Cambridge in 1905. At Christchurch under Prof. Bickerton he constructed a magnetic detector of wireless waves, took a prominent part in debate and as a forward in the football team. According to a fellow pupil at Nelson and Christchurch, Mr. F. Milner, who contributes a foreword to the pamphlet, "whatever Rutherford did as a student he did thoroughly".

Dr. E. Marsden was one of the distinguished band of research students working at Manchester with Rutherford: "Geiger and Marsden made the very striking observation that some of the particles incident on a sheet of matter have their direction changed to such an extent that they emerge again on the side of incidence." ("Radiations from Radioactive Substances", p. 191.) This result started Rutherford on his successful voyage to the nucleus !

Marsden accompanied Rutherford on his last tour in New Zealand and made all arrangements for travel, meetings and lectures. $\mathrm{He}$ has written a good account of Rutherford's youth and given an appreciation of the enormous influence his life and work, his visits and lectures have had on the people of New Zealand. 
Mr. R. M. Laing has contributed a brief article to To-morrow, a New Zealand independent fortnightly (Nov. 10, 1937).

The Nelsonian, the magazine of Rutherford's school, Nelson College, has collected notices and published a photograph of the old Rutherford home since demolished. One of the Houses at Nelson College is now known as Rutherford House.
Dr. C. M. Focker is also preparing a full bibliography of the publications of Lord Rutherford to be given in the Transactions of the Royal Society of New Zealand. The list is still incomplete, but the present number of books, letters and articles has already reached a total of some two hundred and sixty. It will be a valuable index of Lord Rutherford's activities.

\section{The Assessment of Nutrition}

$\mathrm{I}^{\mathrm{T}}$ is not often that a single problem is, at one time, and without deliberate co-ordination, studied by medical men, scientific workers and sociologists. This is the case with the 'assessment of nutrition'. Everyone who is interested should read a contribution* which both shows how urgent the problem is and (by implication, since the author tactfully understates his case) indicates possible modes of solution. Everyone should also read the discussion which follows the paper.

Mr. Huws Jones defines the problem : To discover undernourished children that they may be fed. There is reason to believe the methods in use are not discovering them all. Three possible improvements are suggested; more frequent detailed medical examination, frequent rapid survey to select cases for detailed examination, or the use of a physical yardstick to select cases for detailed examination. Since questions of finance exclude the first suggestion (yearly examination of all children would mean trebling the number of school medical officers), and the second is not considered likely to be useful, attention is concentrated on the third.

The object of the inquiry was to show whether any system of physical measurements can be used to avoid unnecessary extension of medical examination, to select probable cases for the decision of the medical officer. School children were therefore medically examined and carefully measured. Children from the same school were examined by the same doctor on two occasions ; the same children were examined by different doctors; the doctors "were urged to take as much time as they wanted over the assessment of each boy". Finally, the grading of the children by physical measurement and by medical opinion was compared.

The comparison showed that the percentage of children graded by medical examination as subnormal increased steadily from good to poor schools ; that height and weight, at each age, improved with social class ; that of children graded medically in the same nutrition class those in better schools were taller and heavier than those in poorer schools, and that height and weight in all classes of school im. proved with nutrition elass. Nutrition grades, as determined by medical examination, "are distinguished best by weight, then by chest, and finally by height". But no combination of measurements could be found which could be used to pick out exactly the same children as the medical officers would select as a result of their examination.

The discussion is illuminating. Dr. Magee ignored

* Jones, R. H., "Physical Indices and Clinical Assessments of the Nutrition of Schoolchildren" (with Discussion), J. Roy. Statist. Soc., 101, 1-52 (1938). the economic reason for seeking a time-saving substitute for clinical examination and wished to combine anthropometric with clinical examination and even add on physiological tests. Dr. Glover, of the Board of Education, cheerfully delivered himself into the hands of his critic on two counts, first that the discrepancies between the assessments of the different medical men could be explained as due to borderline cases, and second that the judgment of "teachers, school nurses, school attendance officers and others in regular contact with the children... could go far towards filling any gaps left by clinical assessment".

From the former of these suggestions, Mr. Huws Jones deduced that, in some areas, more than half the children examined were on the borderline between satisfactory and unsatisfactory nutrition, which makes the published reports of the Board seem "Too rosy". In view of the second, he wondered what need there is to employ medical men at all for this purpose if teachers appear to be so successful in picking out children who escape the doctors' scrutiny.

Dr. Daley suggested that the important thing was, not the anthropometric measurements at a given moment, but periodic measurements to show rate of growth.

Apart from the general conclusion that physical measurements give an index "at least as satisfactory as a careful and complete clinical examination", the issue is left in doubt. Indeed, Mr. Jones himself questions whether the best index he found (Tux. ford's) can be regarded "as a satisfactory measure of nutrition". But, if the problem be accepted as originally enunciated, namely, to discover under. nourished (that is, underfed) children in want of more food, then, on analogy with animal husbandry, physical measurements are the simplest and only reliable criteria. If, on the other hand, as appears from several parts of the discussion, something more difficult and subtle must be read into the problem, which becomes a complicated mixture of questions of disease and malnutrition, as well as underfeeding, then the role of the doctor appears to be to select from amongst those shown by physical measurement to be below an accepted standard: $(a)$ those whose condition is referable to any detectable disease con. dition not nutritional in origin; and $(b)$ those suffering not from gross lack of food, but from some particular deficiency. The first would receive ap. propriate treatment and all the others would be fed; unless, of course, as $\mathrm{Mr}$. Jones rationally suggestsand his study has given a general indication in favour of this solution-all the children from poor families are fed. 